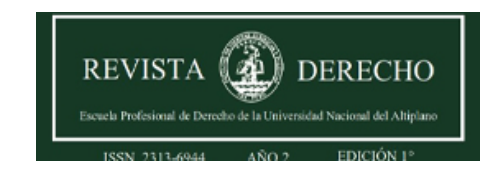

Revista de Derecho

ISSN: 2313-6944

ISSN: 2707-9651

revistaderecho@unap.edu.pe

Universidad Nacional del Altiplano

Perú

\title{
LOS DERECHOS Y DEBERES EN EMERGENCIA
}

\author{
Ccama Cruz, Marina \\ LOS DERECHOS Y DEBERES EN EMERGENCIA \\ Revista de Derecho, vol. 5, núm. 2, 2020 \\ Universidad Nacional del Altiplano, Perú \\ Disponible en: https://www.redalyc.org/articulo.oa?id=671870937010 \\ DOI: https://doi.org/10.47712/rd.2020.v5i2.89
}

\section{(c) (1)}

Esta obra está bajo una Licencia Creative Commons Atribución 4.0 Internacional. 


\section{LOS DERECHOS Y DEBERES EN EMERGENCIA}

\author{
THE RIGHTS AND DUTIES IN EMERGENCY \\ Marina Ccama Cruz \\ Universidad Nacional del Altiplano de Puno, Perú
}

DOI: https://doi.org/10.47712/rd.2020.v5i2.89

Redalyc: https://www.redalyc.org/articulo.oa? id $=671870937010$

Recepción: 30 Septiembre 2020

Aprobación: 25 Octubre 2020

Publicación: 27 Octubre 2020

\section{Resumen:}

En la actualidad con la basta normatividad tanto nacional como internacional sobre la defensa de los derechos humanos, se ha generalizado la protección y el respeto de los derechos sin embargo se olvida por completo la dualidad y correspondencia que existe entre la exigencia de los derechos y el cumplimiento de los deberes, de este modo el cumplimiento de deberes garantiza en si el ejercicio de derechos.

Se ha interiorizado tanto el respeto por los derechos en todos los ámbitos de la sociedad que se ha dejado de lado la concientizacion sobre los deberes, sin entender que nuestro ordenamiento legal tiene su base en la correlación de los derechos y los deberes.

Durante el estado de emergencia en el que nos encontramos uno de los deberes que se ha incumplido de manera mas frecuente ha sido la obligación de asistencia de pensión alimentos, sin considerar que al incumplir este deber por parte de los obligados se afecta el derecho de los alimentistas.

Palabras Clave: Derechos, deberes, correlación, pensión de alimentos.

\section{Abstract:}

At present, with the vast national and international regulations on the defense of human rights, the protection and respect of rights has become widespread, however, the duality and correspondence that exists between the requirement of rights and the fulfillment of duties, thus, compliance with duties guarantees the exercise of rights.

Respect for rights has become so internalized in all areas of society that awareness of duties has been put aside, without understanding that our legal system is based on the correlation of rights and duties.

During the state of emergency in which we find ourselves, one of the duties that has been breached most frequently has been the obligation to provide alimony, without considering that breaching this duty by the obligated parties affects the rights of the parties. feeders.

KEYWORDS: Rights, duties, correlation, alimony.

\section{INTRODUCCIÓN}

Hablar sobre Derechos Humanos en la actualidad puede ser muy redundante, nos encontramos en un estado de emergencia por la Pandemia del COVID-19 y en lo que llevamos de la cuarentena lo que a concurrido reiteradamente es la forma en la cual los ciudadanos en su mayoría se conducen durante esta emergencia, incumpliendo casi por deporte las diferentes normas y leyes expedidas por el ejecutivo, en algunos casos lo atribuyen al hecho de que no tienen una fuente de ingresos que les permita no vulnerar estas normas y tal vez puede ser comprensible por la gran cantidad de personas que viven del día a día, pero hay casos totalmente extremos, fiestas en discotecas improvisadas donde acuden masivamente jóvenes, canchas deportivas llenas cual día de campeonato, mercados en los cuales las medidas de protección dictadas por el gobierno se pasan por alto, ya en casos mas extremos fiestas del personal de salud de alguna posta medica, o personal policial festejando.

Sin embargo estas situaciones extremas que presenciamos hoy no se dan solo en la cuarentena son una constante en nuestra vida diaria con o sin emergencia. 
Es importante que los deberes se planteen como deberes recíprocos de los ciudadanos respecto al Estado, del Estado respecto de los ciudadanos y al mismo tiempo entre ellos. Por lo tanto los ciudadanos deben amor a la patria, servicio y defensa del Estado, participación en la vida política, el deber del trabajo y del cumplimiento de las normas morales y jurídicas. En Reciprocidad el Estado tiene el deber de proteger al ciudadano, en su persona, a su familia, su religión, su propiedad, su trabajo, educación indispensable a todos los hombres, proporcionar asistencia por medio de trabajo, protegiendo a quienes no tuvieran la protección de una familia.

En nuestra Constitución se establecen deberes y derechos. La actual Constitución de 1993, también ha establecido importantes valores al reseñar los deberes y responsabilidades de los ciudadanos, los cuales se encuentran numerados en el Art. 97, y que se resumiría en la necesidad del cumplimiento de nuestros deberes que deriva en el respeto por nuestros derechos, lo cual constituye la razón de ser del propio Estado.

\section{1. - Metodología.}

Se utilizo la metodología cualitativa y se considera principalmente la revisión de textos ya que nos permite describir y analizar los fundamentos teóricos.

\section{¿ Por que consideran las personas que exigir sus derechos es importante y que CUMPLIR SUS DEBERES NO?}

Para muchas personas, la palabra "deber" todavía se refiere a la idea de limitación de derechos, castración de libertades y autoritarismo estatal[1].

Según Dimoulis; Martins, consideran que los deberes fundamentales serían mero "reflejo en el espejo" de los derechos fundamentales, es decir, que éstos serían una mera consecuencia de éstos, como refieren los autores que negaron la utilidad para prever estos deberes.

José Canotilho (2003) refiere que la desconexión entre derechos y deberes, podría ser denominada de "signalagmaticidad o asimetría".

En base a estas referencias los ciudadanos que consideran que los derechos son de obligatorio cumplimiento y que los deberes son opcionales, es decir quien quiere los asume estarían actuando conforme a esta posición. Sin embargo considerando nuestra situación actual podríamos suponer que los ciudadanos estarían dispuestos a cumplir los deberes fundamentales impuestos por el ejecutivo, pero vemos con mucha pena que la exigencia del respeto a los derechos es constante contrario al hecho que no hay ninguna intención del cumplimiento de deberes cuando se debe entender la dualidad de que el cumplimiento de los deberes en todos los ámbitos lleva a la protección de los derechos.

En este contexto José Nabais (2004), considera que la tesis de una completa asimetría entre derechos y deberes fundamentales se equivoca, así como el que admite una superposición completa entre ambas categorías. Lo que existe es una "asimetría parcial", lo que implica que hay una cierta dependencia, ya que no hay derechos sin deberes, ni todo lo contrario, que se deriva del hecho de que ambos, derechos y deberes fundamentales, cumplen el rango constitucional de la persona y, como tales, se someten al mismo régimen general.

Nos encontramos actualmente ante un deber positivo que exige la realización de acciones. Ademas en los instrumentos de derechos humanos se establecen, al mismo tiempo, una serie de deberes. En el artículo 29 de la Declaración Universal de los Derechos Humanos, de 1948, dice que "toda persona tiene deberes respecto a la comunidad, puesto que solo en ella puede desarrollar libre y plenamente su personalidad”. Por otro lado, la Declaración Americana sobre los Deberes y Derechos del Hombre señala deberes ante la sociedad, deber de sufragio, deber de obediencia a la ley, etc. 
Tenemos que considerar que no solamente el Estado tiene deberes, sino también las personas. Esos deberes, son una obligación y también un mandato ético de consideración hacia los demás.

¿Existe correlación entre Derechos y deberes?

Según la Convención Americana sobre Derechos Humanos (San José, 1969).

Artículo 32.- Correlación entre Deberes y Derechos

1. Toda persona tiene deberes para con la familia, la comunidad y la humanidad.

2. Los derechos de cada persona están limitados por los derechos de los demás, por la seguridad de todos y por las justas exigencias del bien común, en una sociedad democrática.

Es primordial insistir en la importancia de la correlación de derechos y deberes para garantizar la viabilidad de los sistemas de derechos fundamentales, ya que algunos derechos presuponen la existencia de un deber. Por otro lado, debe tenerse en cuenta que los deberes fundamentales no son deberes del hombre en general, sino sólo deberes del miembro de la comunidad o del sometido al Estado, es decir, de las personas que se encuentran dentro de la esfera del poder del Estado. (SCHMITT,2001)

Si bien es cierto hay una correlación entre derechos y deberes, la existencia de los deberes como una obligación jurídica no debe entenderse como una condición que limita el disfrute de los derechos.

Por ejemplo La Declaración de Derechos Humanos de la Asean (Asociación de Naciones del Sudeste Asiático) establece entre sus principios generales que el disfrute de los derechos humanos y de las libertades fundamentales debe ser contrapesado con el cumplimiento de los deberes correspondientes. Sin embargo ese enfoque no es congruente con la Declaración Universal de los Derechos Humanos ni con el cuerpo jurídico del Derecho Internacional de los Derechos Humanos. Estos derechos jamás pueden estar condicionados a un cierto comportamiento de los individuos es decir no se puede confundir correlación con correspondencia.

Con esta precisión, resulta claro que existe un fundamento jurídico para reforzar que el cumplimiento de los deberes en una situación crítica como la actual se tiene que dar frente al respeto de las normas de emergencia,no solamente el Estado tiene deberes, sino también las personas. Esos deberes, son una obligación y también un mandato ético de consideración hacia los demás ciudadanos como la responsabilidad y solidaridad.

No se trata, de llevar el cumplimiento de los deberes a los extremos descritos en el diálogo platónico Critón o el deber , cuyo contenido Narra un encuentro entre Critón y Sócrates en la prisión, donde Sócrates asume que el deber de acatar las normas de la ciudad es de tal naturaleza, que se antepone a su vida. En la actualidad se trata de lograr un equilibrio en la correlación entre derechos y deberes.

¿La constitución del Perú contempla tanto los derechos como los deberes, entonces porque se exigen derechos y no se cumplen los deberes?

Muchas veces se piensa que la solidaridad hacia nuestros conciudadanos que son victimas de cualquier situación adversa es solo parte de la buena voluntad de los ciudadanos, sin embargo se debe considerar que esta actitud constituye un deber de cumplimiento obligatorio según lo establece nuestra constitución, sin embargo en la mayoría de los casos cuando las personas colaboran o apoyan en situaciones de adversidad considera que esta realizando un acto admirable, cuando realmente está haciendo lo que corresponde al cumplimiento de los deberes constitucionales que constituyen un pilar fundamental en nuestro estado.

Artículo 22.- El trabajo es un deber y un derecho. Es base del bienestar social y un medio de realización de la persona.

Artículo 31.- Es derecho y deber de los vecinos participar en el gobierno municipal de su jurisdicción. La ley norma y promueve los mecanismos directos e indirectos de su participación.

Artículo 38.- Todos los Peruanos tienen el deber de honrar al Perú y de proteger los intereses nacionales, así como de respetar, cumplir y defender la Constitución y el ordenamiento jurídico de la Nación.

En materia de Derechos Humanos, el Estado es el principal llamado a garantizar, defender y difundir su contenido, tal como se consagra en la Constitución. 
Bobbio (1982), consideraba que el problema del fundamento de los Derechos Humanos estaba resuelto y que la tarea pendiente en este ámbito consiste en:

...no tanto la de saber cuáles y cuántos son estos derechos, cuál es su naturaleza y su fundamento, si son derechos naturales o históricos, absolutos o relativos, sino cuál es el modo más seguro para garantizarlos, para impedir que, a pesar de las declaraciones solemnes, sean continuamente violados.

Con lo que se determina la responsabilidad del Estado para garantizar el cumplimiento de los derechos.

Si bien es cierto existen diferentes posturas respecto de la exigibilidad de los deberes considerando como una postura que los deberes constitucionales carecen de exigibilidad; u otra postura que refiere, que son plenamente exigibles; podríamos asumir más bien que la declaración de deberes constitucionales tiene una serie de efectos prácticos que van más allá de la sola habilitación para su obligación y de la directa exigibilidad de los mismos ya que no se podría sostener que el cumplimiento de deberes constitucionales carezcan de todo sentido práctico o útil; en la actualidad estamos en una situación ante la cual este cumplimiento de deberes es en realidad un precepto que si haría la diferencia, de este modo si la constitución nos avala al momento de exigir nuestros derecho, es también la constitución que rige sobre el cumplimiento de los deberes.

En la Constitución no se establece sanciones para el supuesto de incumplimiento, es decir que de su solo enunciado no surge ningún deber forzoso para ningún ciudadano, quizá podría tener fuerza normativa en la medida que se desarrolle de forma legislativa, dejando de este modo establecidas sus condiciones de ejercicio, limitaciones y garantías. Sin embargo, de aceptarse tal conclusión, sería inútil contemplar deberes de rango constitucional y bastaría con imponerlos mediante normas legales.

¿Y el deber de pagar pensión de alimentos en cuarentena?

Considerando lo anteriormente expuesto, un claro ejemplo de la correlación que existe entre derechos y deberes podríamos decir que seria la pensión de alimentos que es un deber para el obligado y un derecho para el alimentista. Sin embargo el pago de las pensiones de alimentos con la crisis que estamos viviendo a causa de los efectos del Covid-19, la cuarentena y las demás medidas adoptadas por el Gobierno no están siendo cumplidas. Por lo que se debe advertir que la pensión de alimentos de los hijos tienen una especial protección en materia de familia, por lo tanto esta obligación tiene que cumplirse, según la situación del obligado al pago ya que de ningún modo esta obligación puede cesar o dejar de cumplirse. Existen muchos casos como:

El caso de un obligado al pago de pensiones que debido a la crisis del Covid-19 ve suspendida completamente su actividad, que no le es posible el pago de pensiones que se establecieron en una sentencia o una conciliación, cuando su situación económica y empresarial era completamente distinta.

El caso de los hijos de una familia acomodada, cuyas pensiones de alimentos se han fijado muy por encima de lo que son las necesidades de los hijos en cuanto a alimentos, higiene, etc., por el hecho de que el progenitor obligado al pago tuviese una situación económica holgada al momento de la sentencia o conciliación.

También hay casos en los que el obligado con la excusa de la cuarentena y el estado de emergencia no pagan la pensión de alimentos simplemente con la intención de eludir esta obligación, aun considerando que su situación económica al momento de establecerse la pensión no ha cambiado.

Y muchos otros casos, sin embargo es importante recalcar que este deber de pagar la pensión de alimentos si tiene una sanción debido que el incumpliento de este deber vulneraria el derecho del alimentista, razón por la cual se tiene que pagar esta pensión aun cuando la capacidad económica real y actual del obligado al pago de la pensión no sea la mejor y podría verse reducido proporcionalmente.

En la ley no se tiene nada previsto respecto del tema de pensión de alimentos en una situación como la que estamos viviendo sin embargo considero que no hay razon de cese de esta pensión, si acaso una reducción que no afecte lo imprescindible y necesario. 


\section{CONCLUSIÓN}

El sistema de deberes constitucionales se estructura sobre el principio de reciprocidad. El Estado asume ciertas tareas y garantiza el ejercicio de derechos y libertades, pero a su vez requiere de la participación de todas los ciudadanos, de esta forma complementa la gestión pública, la exigencia de cumplir con nuestros deberes no implica que se vulnere del ejercicio de derechos.

En cuanto al estado de emergencia en el que nos encontramos la exigencia en el cumplimiento de los deberes depende no sólo del sujeto del deber sino también del derecho fundamental correlacionado que se intenta proteger especialmente en aquellas situaciones en las que la sociedad es beneficiaria.

Durante la cuarentena en la que nos encontramos muchos derechos han sido vulnerados debido a que muchos deberes no se cumplieron y en realidad estos problemas que no pasan solo en época de emergencia, porque son problemas constantes que tienen que ser entendidos desde una perspectiva no solo de derechos humanos sino también de deberes.

El estado tiene mucha responsabilidad ya que se ha difundido el respeto por los derechos y es hora que instituciones como poder judicial, y otras se avoquen a una difusión sobre los deberes, también se tiene que tener estos temas en los colegios que es donde las personas forman sus valores y también en las familias ministerios de justicia,ministerio de educación, ministerio de la mujer, etc,. No se puede seguir por el mismo camino de remediar situaciones, se tiene que poner mayor énfasis en la prevención porque observamos que a pesar de la penalizacion de las deudas por pensión de alimentos muchos padres o madres siguen sin asumir ese deber ya que tienen que ser obligados.

También en un sentido mas amplio el poder judicial debería de contemplar la posibilidad de la revisión de urgencia de los diferentes, examinando qué es aquello que es verdaderamente sustancial y que deben los progenitores hacer un esfuerzo por mantener, de aquello que no lo es.

\section{BIBLIOGRAFÍA}

BOBBIO, Norberto Presente y porvenir de los derechos humanos, Anuario de Derechos Humanos: Instituto de Derechos Humanos, Facultad de Derecho, Universidad complutense, Madrid, España, 1982

CANOTILHO, José Joaquim Gomes. Direito constitucional e teoria da Constituição. 7. ed. Coimbra: Almedina, 2003.

CONSTITUCION POLITICA DEL PERÚ

CONVENCIÓN AMERICANA SOBRE DERECHOS HUMANOS (San José, 1969)

CRITÓN O EL DEBER. Editorial Porrúa, México D.F, 2003

DECLARACION DE DERECHOS HUMANOS DE LA ASEAN (Asociación de Naciones del Sudeste Asiático)

DIMOULIS, Dimitri; MARTINS, Leonardo. Deveres Fundamentais. In: LEITE, George Salomão; SARLET, Ingo Wolfgang; Carbonell, Miguel [Coords.]. Direitos, deveres e garantias fundamentais. Salvador: Juspodvium, 2011, p. 325-45.

NABAIS, José Casalta. O dever fundamental de pagar impostos: contributo para a compreensão constitucional do estado fiscal contemporâneo. Coimbra: Almedina, 2004.

SCHMITT, C. Teoría de la Constitución. Madrid, Alianza Editorial, 2001.

TAVARES, Henrique da Cunha; PEDRA, Adriano Sant'Ana. (2013). As obrigações tributárias acessórias e a proporcionalidade na sua instituição: uma análise a partir da teoria dos deveres fundamentais. Revista Tributária e de Finanças. 
Revista de Derecho, 2020, vol. 5, nÚM. 2, Agosto-Diciembre, ISSN: 2313-6944 / 2707-9651

\section{Notas}

[1] Tavares y Pedra (2013), pp. 203-223. 